\title{
Balance of Economic and Social Factors in Environmental Projects
}

\author{
Anna F. Gordova 1[ORCID 0000-0001-9928-213X], \\ Nikolay M. Tverdynin 1[ORCID 0000-0003-0678-0768], \\ Lilia R. Sharifullina 1[ORCID 0000-0002-3384-2007], \\ Olga A. Tikhonova $\left.{ }^{2 *[O R C I D} 0000-0002-2255-4667\right]$, \\ Nadezhda I. Grishakina 3[ORCID 0000-0002-1693-8840]
}

\author{
1 Civil Defence Academy of the Ministry of the Russian Federation for Civil Defence, Emergencies and \\ Elimination of Consequences of Natural Disasters, Moscow Region, Russia \\ ${ }^{2}$ Russian State Research Center - Burnasyan Federal Medical Biophysical Center, Federal Medical Biological \\ Agency, Moscow, Russia \\ ${ }^{3}$ Yaroslav-the-Wise Novgorod State University, Veliky Novgorod, Russia \\ ttx_2001@mail.ru
}

\begin{abstract}
With a more than significant interest in environmental issues in society and the widespread introduction of environmental themes in the social and educational space, a number of methodological and methodical problems remain unresolved. These problems are connected, on the one hand, with comparative assessments of environmental measures, taking into account both their ecological significance and economic viability, and, on the other hand, they relate to building a system of priorities in the presentation of material reflecting the realities of environmental policy in the study of ecology at different levels of education and in different subject areas. The article discusses methodological approaches and model ideas for assessing the viability of economic investments in environmental activities, taking into account both social and economic factors. Approaches to the description of the relationship of scientific and technological parameters with the formation of conditions for the economically profitable introduction of new technologies, when the need to solve environmental problems is a stimulating factor, have been considered, and the concept of an Economic and Environmental Barrier reflecting the level at which old technological solutions, although they satisfy technological requirements, but no longer meet environmental requirements is introduced. It is shown that, other things being equal, the economic component is to dominate over the environmental one when making decisions on financial investments in environmental projects. However, mobilizing public opinion in support of environmental initiatives can change attitudes towards assessing the economic viability of projects related to environmental protection. This especially applies to public funding of environmental initiatives, including in the field of environmental education. At the same time, an assumption is made about the significant dependence of the perception of scientific and popular scientific information on ecology on the level of social protection of the population and the level of its economic well-being. The authors suggest that the multifactorial nature of environmental parameters requires new approaches to environmental awareness-raising, causing a broader understanding of intersubject interaction with noxological and medical rehabilitation topics.
\end{abstract}

Keywords: ecology and economics, social priorities, limit of ecological and economic parameters, environmental awareness-raising, environmental education

\section{INTRODUCTION}

Discussion of environmental topics at any level and in any social community over the past halfcentury, i.e. since the early 1970 s, has become one of the most demanded segments of public life 
throughout society. To date, the need for environmental education is firmly established in the minds of the vast majority of people in developed countries.

The authors understand environmental education as an educational and cultural process, during which students acquire competencies related to a general theoretical understanding of the importance of environmental problems, and also assimilate values that allow them to foster an understanding of the complexity of the natural scientific, technical, and humanitarian aspects of the safety of the natural and technogenic environment, to prevent and/or solve environmental problems. Nevertheless, no unified methodology has been developed in relation to this rather diverse component of the educational space. There are several reasons for this.

To begin with, education as a social institution is one of the most inert social systems. While verbally recognizing the need for innovation and without questioning the educational value of environmental issues, the administration does not seek changes that would alter the situation in such a way that it itself becomes unnecessary. Namely, widespread environmental awareness-raising makes the activities of the majority of education officials who "lead" environmental education unnecessary.

Another reason that environmental education remains fragmented is the economic factor. A real environmental policy aimed both directly at protecting the environment and measures to maintain it at the current level, and even more so to improve it, requires significant economic investments. Although in several publications $[1,2]$ one can read about successful environmental projects within green economics, at the same time, it is also indicated there that government support remains one of the main sources of funding for such projects. That is why environmental education is financed in such a way that with a large number of activities, the question of their effectiveness is left open since real environmental research and their material support are very costly. The same applies to environmental education activities, especially in higher education.

That is why the economic issues associated with the educational segment of ecology are closely intertwined with socio-political processes. Large scale changes in the quality of the environment recorded in the 21 st century [3] required the transformation of traditional environmental education into Environmental Education for Sustainability (EES) [4-6], which should ensure the safety of the technosphere not only for today's but also for future generations.

To defeat hunger by ensuring the functioning of sustainable agriculture, to switch to a healthy lifestyle by reducing air, water, and soil pollution, to create the opportunity for economic growth by increasing the efficiency of resource use without degrading the environment [3], to make and implement decisions, quality revitalization and growth of human potential are essential. These should be people whose education includes knowledge of the essence and goals of sustainable development. The level of incorporation of EES in higher education programs of various (nonenvironmental) areas and specialties is an urgent modern problem for the world community [5].

Modern business, integrated into the global economy, has to solve a wide range of social and environmental problems. The lack of components aimed at ensuring sustainable development in the company's activities undermines its authority in the world arena and makes it unattractive for investors. Coordination of the strategy and tactics of the enterprise with the goals of sustainable development, reduction of resource intensity, energy intensity, and the amount of waste gives an advantage in world markets [7, 8]. Tools for assessing the level of incorporation of EES in vocational education programs, as noted above, are being successfully developed [5] and should take into account the needs of both each country and spheres of professional activity.

Currently, due to the rapidly changing requirements for specialists in various industries, it is important to create online courses both for students (undergraduates, master students) and for specialists wishing to improve their qualifications [9]. One can even use records of excursions from museums [10] and videos of laboratory experiments to conduct online practical exercises.

The purpose of higher education institutions today is not limited to the organization of the educational process and scientific research. The functions of the institution of higher education include awareness-raising and information work [5, 11], the purpose of which is to bring to the established members of society (no longer students) information about modern problems of economics, politics, ecology (environmental protection), sustainable development, etc.

The link between modern economic and environmental priorities that also indirectly connects 
economic and environmental education is the concept of corporate sustainable development [12].

Another component that ensures the quality of environmental education is the competence-based approach in education, which allows you to draw up a "road map" to achieve a specific result, which should contribute to the implementation of the goals of EES [13].

However, we do not yet have indisputable theoretical data and data from applied environmental research that would allow for the transition from general cultural competencies to professional competencies that accumulate environmental theories with their practical application. These two segments, rather, function separately than form a single whole for now. [13].

Nevertheless, there are some successes in the development of practical methods. Methodologies are being developed for a practical component devoted to sustainable development, which can and should be included in university programs [14]. Works that reflect the chemical component of environmental education are very interesting [15, 16]. Also interesting is the work in which environmental issues are associated with classical economics [17].

The plurality of opinions on the issue of modern environmental education indicates a significant interest in this interdisciplinary problem of the scientific community and its relevance.

\section{MATERIALS AND METHODS}

The material for this study was the data obtained during a survey of students, members of courses, and graduate students of various Moscow universities. At the same time, students and cadets of the Civil Defence Academy of the Ministry of the Russian Federation for Civil Defence, Emergencies and Elimination of Consequences of Natural Disasters, who studied Technosphere Safety in 2019-2021, formed the basis. In addition, materials from surveys of students of various faculties of the Moscow City University, conducted in 2016-2019, were involved. The respondents were students and employees of the technological, chemical-biological, and philological faculties. The total number of respondents was over 1.100 . Thus, it has been possible to form a database that allows modeling the processes associated with the perception of the problems discussed in this article, both among those students who directly perceive environmental topics as an area related to their future professional activities, and those who understand environmental topics only partially or perceives it in a popular science rather than a scientific way. In addition, almost all students and course members surveyed are significantly influenced by the material they receive from various resources of the Internet space. This aspect has also been analyzed in the course of this study.

The main methods that have been used in the work are the method of comparative analogy, the analytical method, the survey method with the subsequent formalization of indicators, programs, and the author's method of comparative modeling of heterogeneous processes and systems by methods of mathematical statistics.

The research objectives include four main areas: 1) analysis of the relationship between the main segments of modern environmental education; 2) consideration of the place of environmental education in the value system of students in educational institutions of the higher education system; 3) analysis of the assumption about the emergence of interest in environmental education only after environmental issues become not only relevant, but require a simultaneous response to problems that have arisen in the course of development, not only from specific people or social groups (professional communities or communities united by place of residence) but are embedded in the main socio-political priorities of the whole society and are included in socio-political activities; 4) determination of the prerequisites for the emergence of conditions when environmental issues become so important that society focuses on the simultaneous solution of two problems: the creation of qualitatively new resource-saving technologies and the simultaneous activation of the use of these qualitatively new technologies which make it possible to eliminate outdated technologies that created environmental problems.

\section{RESULTS}

Analysis of literature data has shown that there is a significant difference in points of view on the state and development of environmental education. It must be stated that the interest in it is quite great and its propaganda, both in the field of awareness-raising and popularization of scientific knowledge, and inclusion in training programs for different levels of education is quite high. In Russia, at present, there is simply no higher educational institution or college, where an ecology course would not be introduced for almost any field of education, or a significant 
amount of environmental information would not be included in general education courses.

At the same time, the study of the patterns of sustainable development in relation to the environment and the technosphere make up a fairly significant part of the knowledge gained in the educational process. It would seem that the picture should correspond to Figure 1, which shows not only the connection of ecology with other subject areas but also informational complementarity since ecology as a complex area also generates interdisciplinary interaction.

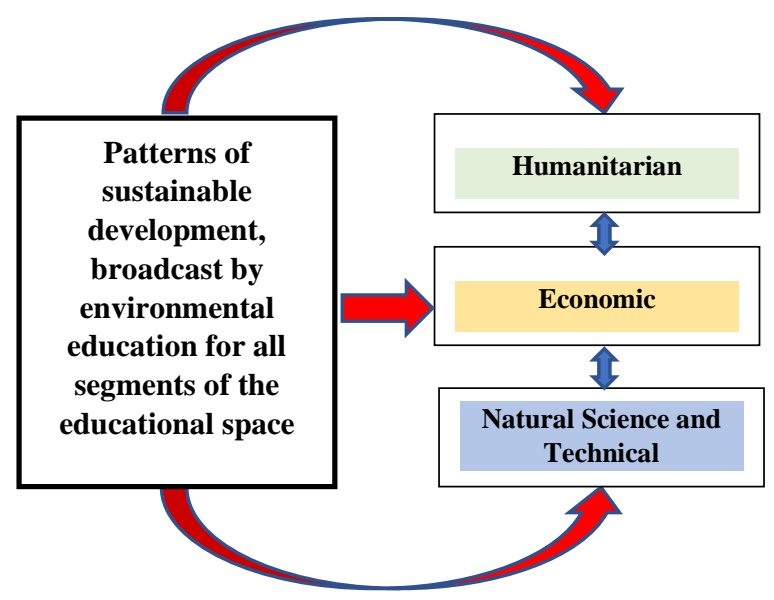

Figure 1. Scheme of interdisciplinary interaction of ecology with various segments of education Source: Compiled by the authors

However, the analysis of more than two hundred publications of student works in the framework of various student scientific conferences devoted to environmental issues in 2018-2021 does not confirm this. The initial selection, carried out by keywords, so that the words "ecology", "ecological" are present in the title of the work, has shown that the most active are students in the humanities. Economists pay relatively much attention to environmental problems, which can be explained by the fact that questions of the economic justification of any environmental project are mandatory. Students in the natural sciences and technical fields of study touch on environmental issues less often. At the same time, those student publications and reports, the authors of which could be considered ecologists in their future profession (for example, Engineering Ecology students) were not considered.

Thus, we can conclude that the interdisciplinary nature of ecology is not yet too accepted by representatives of different categories of students, and information of an interdisciplinary nature is interpreted, rather, within the framework of ordinary, rather than scientific perception. Although students in the humanities turn to environmental topics more often than others, their interest is not associated with a scientific vision of environmental problems but is most often caused by various PR companies and the "fashion", that has been sustained in recent decades, for problems related to environmental protection.

When processing the questionnaires of students, it has been found that students of humanitarian areas (at least $70 \%$ ) in one way or another have a negative attitude to scientific and technical measures to protect the environment and are, rather, in positions of support for the ideas of curtailing hazardous industries, and not their modernization and replacement with qualitatively new technologies. Technicians take exactly the opposite position: about $80 \%$ believe that without scientific and technological progress, environmental problems cannot be solved. Economics students occupy an intermediate position in their assessments: they are mostly characterized by an opinion about the importance of all factors that can influence the decision on the need for specific measures aimed at protecting the environment.

What makes the environmental topic so relevant that it causes not just any changes in technologies and the replacement of outdated technical solutions with more advanced ones but focuses attention if not of the entire society but most of it on environmental issues? Let us further consider the scheme of a technological crisis that can develop into an ecological crisis due to the depletion of resources in various technological areas (Figure 2). This diagram shows how the limit is reached in the development of technologies that were once generally accepted and even advanced, but in the process of their development gradually ceased to meet the interests of society and began to be perceived as nonecological.

An example of such a technology is the technology of using coal in metallurgical production. Initially, only charcoal was used as a reducing agent for metals from the oxidized state in the ore to obtain metals. With the beginning of the accelerated development of industrial production in some European countries, the disappearance of forests began, which could not but affect the general ecological situation. The development of metallurgy has led to the emergence of qualitatively new technologies for the use of coal. Further improvement of steam engines led to qualitatively new problems of a technogenic nature. The result 
was the restoration of virtually destroyed forest ecosystems in Western Europe.

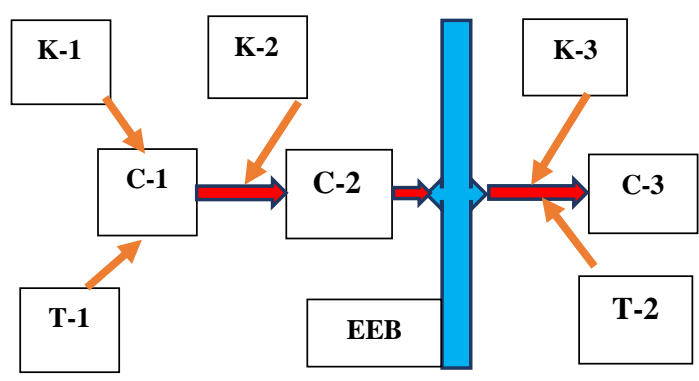

Figure 2. Scheme of the formation of an Ecological and Economic Barrier (EEB) when the possibilities of various technologies (processes, structures) are exhausted

Source: Compiled by the authors

In Figure 2, it is shown that any technical or technological solution (construct), indicated by the square $\mathrm{C}-1$, is a consequence of the interaction of the existing level of knowledge (K-1) and available materials (T-1). With the further development of the construct (machines, mechanisms, technologies), there is an accumulation of new knowledge $(\mathrm{K}-2)$, which allows the creation of a new, more perfect construct (while new knowledge can also lead to a change in the original material). This cycle can be repeated several times until the technical and technological capabilities are exhausted and the limit of ecological and economic parameters is reached. Production for most of its segments will become economically unprofitable, and environmental risks, due to the increase in quantitative indicators, will become dominant. In Figure 2, this moment is reflected in the form of the Ecological and Economic Barrier (EEB). An example of overcoming such a barrier is the replacement of coal-fired steam engines with internal combustion engines and electric motors.

It should be noted that the depletion of certain natural resources due to their unrestrained exploitation, negative climate change, and other factors negatively affecting society, and various crises arising, for this reason, have haunted humanity since the Stone Age. Often such crises, perceived as environmental, are more complex, as pointed out by J. Diamond in his famous popular science work "Collapse: How Societies Choose to Fail or Succeed" in 2005. At the same time, he showed that such crises can both lead to the death of the community that is experiencing it, and can be overcome, although the environmental damage can be very great and even catastrophic. The role of new technologies in the implementation of a positive scenario can be very significant.

To optimize the tasks associated with the negative consequences of the impact of outdated technologies on the environmental situation, to analyze the prerequisites for the emergence of conditions when society focuses on creating qualitatively new technologies and at the same time activating their implementation to solve environmental problems, a model has been developed, a simplified diagram of which is shown in Figure 3. The diagram shows two provisions of the socio-economic system that correspond to the interaction of economic and socio-political factors that make it possible to implement environmental measures that were initially economically inexpedient. Of course, this scheme does not repeat the conditions of equilibrium in the mechanical system of forces, but only correlates the conditions for the balance of factors with the problem familiar to many from the field of mechanics.

When a society already has a social order for qualitatively new and more environmentally friendly technologies, they are often not economically viable. In this case, the economic costs, shown by arrow 1, neutralize the desire to change the situation associated with high costs (arrow 2) with all the environmental benefits (the figure shows the case of marginal "equilibrium"). However, if socio-political interests contribute to the introduction of resourcesaving technologies, then the "lever arm" is "lengthened" (arrow 5) and, despite the high costs, society begins to lean towards the need to implement a more expensive but more environmentally friendly project (arrows 3 and 4 correspond to this provision).

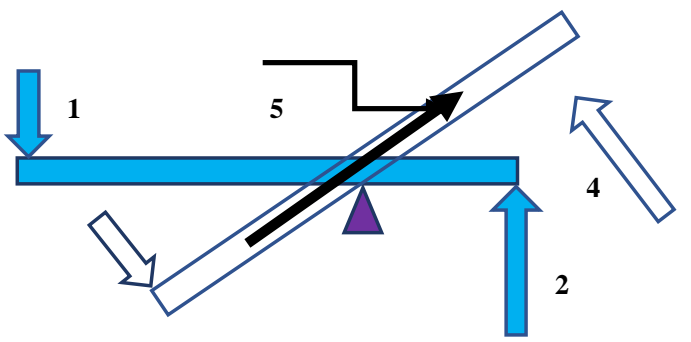

Figure 3. Scheme of the interaction of economic and socio-political factors in the introduction of new, more environmentally friendly technologies Source: Compiled by the authors

Thus, it can be stated that all the stated objectives of this study have been solved to varying degrees.

\section{DISCUSSION}

Based on the work done, it can be concluded that 
in order to improve environmental education, simultaneous processes of differentiation are necessary, in relation to subject areas and levels of education. In addition, environmental education should be considered as part of educational policy. Hence the need for a socio-political analysis of this segment of education when considering its possibilities for implementation of environmental issues in the educational process both as an independent component and as components of individual subject areas.

Speaking about the possibility of modeling economic and ecological systems, it should be noted that, in addition to the methodological value for ecological-economic education, such models are also capable of performing a predictive function when evaluating various projects of ecological content.

\section{CONCLUSION}

It appears that the method proposed in this article for assessing the role and significance of social parameters in environmental education has wider possibilities than the specifics of the educational space. The need to improve the economic study of environmental projects, on the one hand, and the increasing politicization of environmental issues, on the other hand, lead to the understanding that even the most perfect forecast using purely mathematical models does not take into account a number of circumstances that somehow distort the overall picture. Complex models cannot be long-term not only because of the large number of parameters. The constant emergence of new materials and technologies introduces a rather large uncertainty in the long-term planning of socio-political processes. This creates even greater uncertainty in the assessment of environmental problems. That is why the political, economic, technological, and social assessment of various environmental projects and initiatives, including environmental education, is very ambiguous. The approaches proposed in the article, as the authors hope, are to help in solving the problems described in the article.

\section{AUTHORS' CONTRIBUTIONS}

Anna F. Gordova: research design; obtaining data for analysis. Nikolay M. Tverdynin: analysis of existing views and concepts; manuscript text. Lilia R. Sharifullina: research framework design; interpretation of the data obtained. Olga A. Tikhonova: final approval of the article; research concept and manuscript text. Nadezhda I. Grishakina: analysis of existing views and concepts; review of publications on the topic.

\section{REFERENCES}

[1] S.G. Tyaglov, R.M. Bogdanova, E.V. Parada, "Development of green economy within implementation of the national ecology project", Finansovye Issledovania, 2019, vol. 2(63), pp. 13-22. (In Russ.).

[2] T.N. Sedash, E.B. Tyutyukina, I.N. Lobanov, "Directions and instruments of green projects financing within the concept of sustainable development of the economy", Economics, Taxes and Law, 2019, vol. 12(5), pp. 52-60. (In Russ.). DOI: 10.26794/1999-849X-2019-12-552-60

[3] O. Mironenko, P.L. Lucas, N. Tarasova, Ja. Zlinszky, "Sustainable development goals: why do we need them?", Social Evolution and History, 2015, vol. 14(2), pp. 176-190.

[4] N.N. Marfenin, L.V. Popova, "Systemic Basis in Education for Sustainable Development", Scholarly Notes of Transbaikal State University, 2020, vol. 15(4), pp. 16-25. (In Russ.). DOI: 10.21209/2658-7114-2020-154-16-25

[5] M.D. Luna-Krauletz; L.G. Juárez-Hernández, R. Clark-Tapia, S.T. Súcar-Súccar, C. AlfonsoCorrado, "Environmental Education for Sustainability in Higher Education Institutions: Design of an Instrument for Its Evaluation", Sustainability, 2021, vol. 13, p. 7129. DOI: $10.3390 /$ su 13137129

[6] G.D. Boca, S. Saraçli, "Environmental Education and Student's Perception, for Sustainability", Sustainability, 2019, vol. 11, p. 1553. DOI: $10.3390 /$ su 11061553

[7] E.Y. Panasenkova, "The effect of sustainable development factors on the strategic policy of universities", XXI century. Technosphere Safety, 2020, vol. 5(2), pp. 146-156. (In Russ.). DOI: $10.21285 / 2500-1582-2020-2-146-156$

[8] N.N. Trofimova, "Concept of Sustainable Development as Strategic Basis of Business Reputation for Enterprises of Real Sector of Economy", Surgut State University Journal, 2020. vol. 3(29), pp. 36-44. (In Russ.). DOI: 10.34822/2312-3419-2020-3-36-44

[9] L. Popova, M. Pikulenko, “Teacher's Readiness to Create Own Online Courses", in Proceedings 
of the ARPHA Proceedings 3: VI International Forum on Teacher Education, Pensoft Publishers (Bulgaria), 2020, vol. 3, pp. 20172031. DOI:10.3897/ap.2.e2017

[10] M.M. Pikulenko, L.V. Popova, I.P. Taranets, "The role of educational technologies in the sustainability of urban ecosystems", in Proceedings of the EUROGEO 2021 Conference Sustainable Development for all (Book Abstracts), Universidad Nacional de Educacion a Distancia (Spain), 2021, vol. 1, pp. 66-67.

[11] A.S. Jadhav, V.V. Jadhav, P.D. Raut, "Role of Higher Education Institutions in Environmental Conservation and Sustainable Development: A case study of Shivaji University, Maharashtra, India", Journal of Environment and Earth Science, 2014, vol. 4(5), pp. 30-34.

[12] S. Kuzubov, "Sustainability: A New Paradigm of Corporate Reporting", Journal of Corporate Finance Research, 2017, vol. 11(4), pp. 7-10. DOI: 10.17323/j.jcfr.2073-0438.11.4.2017.7-10

[13]A. Karatkevich, "Definition of the concept and content of universal competences of university graduate for education for sustainable development", in Proceedings of the Sakharov Readings of 2019: Environmental Problems of the XXI Century. Materials of the 19th international scientific conference. In three parts, In Ed. by S.A. Maskevich, S.S. Poznyak, 2019, pp. 24-27. (In Russ.).

[14]C.R. Colombo, A.C. Alves, "Sustainability in engineering programs in a Portuguese Public University", Production, 2017, vol. 27(spe), p. 20162214. DOI: 10.1590/0103-6513.221416

[15]M.S. Pak, "Possibilities of the noxological approach in the development of the theory and methods of teaching chemistry" [Vozmozhnosti noksologicheskogo podkhoda $\mathrm{v}$ razvitii teorii $\mathrm{i}$ metodikimobucheniya khimii], in Research of various directions in the development of psychology and pedagogy: collection of articles of the ISPC. In 2 parts, Ufa: MTSI OMEGA SANES Publ., 2016, part 2, pp. 4-6. (In Russ.).

[16]M.S. Pak, "Noxological aspects in the methodology of chemical and pedagogical education" [Noksologicheskiye aspekty v metodologii khimiko-pedagogicheskogo obrazovaniya], in Proceedings of Evolution of modern science, Kazan: NITs Aeterna Publ., 2015, pp. 114-118. (In Russ.).

[17] Tsvetkov A.V., "Great book about the main problem" [Velikaya kniga o glavnoy probleme], in Preface to Karl Marx's Das Kapital [Predisloviye k Kapitalu Karla Marksa], 54 p. (In Russ.). 